\title{
DUEfPC/91334..T14.4
}

FINAL TECHNICAL REPORT

September 1, 1991 through August 31, 1992

\section{Project Title: CARBONATION AS A BINDING MECHANISM FOR COAL/CALCIUM HYDROXIDE PELLETS}

\author{
Principal Investigator: David M. Rapp. Illinois State Geological Survey (ISGS) \\ 615 E. Peabody Drive \\ Champaign, IL 61820 \\ (217) $244-4991$
}

Co-Investigators:

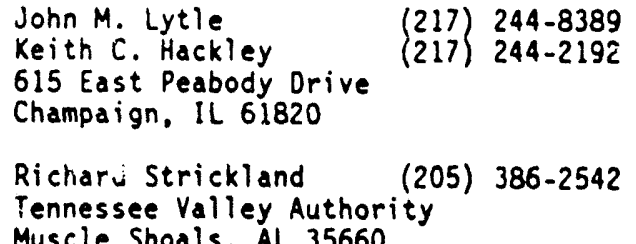

Project Monitor: Or. Dan Banerjee

\author{
Richard Berger (217) 333-6961 \\ University of 111 inois (UI-UC) \\ Civil Engineering Department \\ Champaign. IL 61820 \\ Gary Schanche (217) 398-5505 \\ Construction Engineering Research Lab \\ Champaign, IL 61820
}

\section{ABSTRACT}

In this project, the ISGS is investigating the pelletization of fine coal with calcium hydroxide, a sulfur-capturing sorbent. The objective is to produce a readily-transportable fuel which will burn in compliance with the recently passed Clean Air Act Amendment (CAAA). To improve the economics of pelletizing, carbonation, or, the reaction of carbon dioxide with calcium hydroxide, which produces a binding matrix of calcium carbonate, is being investigated as a method of hardening pelletized coal fines. This report is for the first year of a two-year research program.

This year, pellets were produced from $28 \times 0$ coal fines collected from an Illinois preparation plant using a laboratory version of a California Pellet Mill (CPM), a commercially available pellet machine. The CPM effectively pelletized coal fines at the moisture content they were dewatered to at the plant. Carbonation nearly doubled the strength of pellets containing 10 wt\% calcium hydroxide.

Other results from this year's work indicate that inclusion of calcium hydroxide into pellets resulted in chlorine capture of approximately 20 wt\% for combustion tests conducted at both 850 and $1100^{\circ} \mathrm{C}$. Arsenic emissions were reduced from near $38 \mathrm{wt} \%$ at $850^{\circ} \mathrm{C}$ to essentially nil with inclusion of $10 \mathrm{wt} \%$ calcium hydroxide into the pellets. At $1100^{\circ} \mathrm{C}$, arsenic emissions were reduced from about $90 \mathrm{wt} \%$ to about $15 \mathrm{wt} \%$. Sodium emissions, however, increased with the addition of calcium hydroxide. At $850^{\circ} \mathrm{C}$, sodium capture dropped from about 98 wt $\%$ to 73 wt $\%$ for pellets containing 10 wt\% calcium hydroxide; at $1100^{\circ} \mathrm{C}$, capture dropped from about 92 wt \% to about 20 wt\%.

Also this year, cellulosic residue from the Tennessee Valley Authority (TVA) acid hydrolysis processing of newsprint to produce ethanol and furfural was determined to function as a binder for coal fines, the relative effectiveness of which would depend on the cost of the TVA residue.

This project is funded by the U. S. Department of Energy (PETC) and by the Illinois Department of Energy and Natural Resources as part of their costshared programs. 


\section{EXECUTIVE SUMMARY}

Each year in Illinois, 2-3 million tons of coal fines (approximately 5\% of the State's annual production), are disposed of in tailing ponds because fine coal is difficult to handle and transport. Pelletizing with calcium hydroxide, a sulfur capturing sorbent, represents a method to improve the marketability of these fines. The objective is to produce a readilytransportable fuel which will burn in compliance with the impending sulfur dioxide emissions limits imposed by the Clean Air Act Amendment (CAAA).

To improve pellet quality, the reaction of calcium hydroxide with carbon dioxide is being investigated. Referred to as carbonation, the reaction results in the formation of a bonding matrix of calcium carbonate. The reaction has been tested on a pilot-scale as a method of hardening iron ore pellets formed with a calcium hydroxide. Carbonation has also been investigated as a method of rapidly curing cement. The reaction rate is slow at atmospheric levels of carbon dioxide $(0.33 \%)$ but increases substantially at higher concentrations.

This report is for the first year of a two-year program. The research encompasses pellet production methods, investigation of particle size and moisture on pellet quality, laboratory combustion testing, and determination of the effect of such parameters as carbon dioxide gas concentration and temperature on the carbonation reaction.

As part of this year's effort, a laboratory version of a California Pellet Mill (CPM), a commercially available pelleting machine, was evaluated for effectiveness at pelleting Illinois coal fines. Pellets were preparec at CPM's Crawfordsville, Indiana, facility using $28 \times 0$ coal fines collected from a south-central Illinois preparation plant. The fines were dewatered at the plant to 20 wt\% moisture by a screen bowl centrifuge and were pelletized at this moisture content.

The results indicate that the CPM is an effective method of pelletizing 28 $x 0$ Illinois coal fines. The CPM pellets were uniformly better than pellets prepared with similar binder content at the ISGS laboratory using a hydraulic press.

Pellets were produced at Crawfordsville, returned to the ISGS in sealed containers, and tested for mechanical strength. Pellets were tested at the moisture content at which they were formed (called the green strength), and also after drying. Testing was performed using an Instron strength testing machine and was performed by placing a pellet on its side, applying a force at $0.1 \mathrm{~mm} / \mathrm{minute}$, and measuring the load to failure. Generally when a pellet failed, it broke into a shape resembling a half cylinder and did not disintegrate.

The CPM was used to produce $1 / 4$ " pellets containing no binder, 10 wt\% calcium hydroxide, and $2.5 \mathrm{wt} \%$ corn starch. The strongest dried pellets were the pellets formed with corn starch which had a strength of 42 lbs. The pellets formed without binder had a strength of only 2.5 lbs. The non-carbonated pellets containing calcium hydroxide had a compressive strength of 12.5 lbs with compressive strength increasing after 5 minutes 
of carbonation to 19.5 lbs. The carbonating gas was $100 \%$ commercial grade carbon dioxide.

Although the starch bound pellets had a high cured strength, the green strength was quite low at 2.5 lbs. Drying increased the strength of the starch bound pellets more than ten-fold. The carbonated pellets had a green strength of 11.2 lbs, over four times more than the starch bound pellets. The non-carbonated pellets had a strength more than triple that of the starch bound pellets at 8.5 lbs. The green strength is quite important because this gives an indication of the ability of a pellet to withstand handling after formation. If a pellet has a low green strength, it is likely to break apart during handling, increasing fines formation.

An engineer from CPM estimated the cost of pelletization using a CPM to be $\$ 6.50-8.00 /$ ton, including the cost of depreciation, taxes, power, maintenance, die and roll, and labor, but excluding binder cost.

Other results from this year's work indicate that inclusion of calcium hydroxide into pellets resulted in chlorine capture of approximately 20 wt \% at both 850 and $1100^{\circ} \mathrm{C}$. At $850^{\circ} \mathrm{C}$, arsenic emissions were reduced from near $38 \%$ to essentially nil with inclusion of 10 wt\% calcium hydroxide into the pellets. At $1100^{\circ} \mathrm{C}$, arsenic emissions were reduced from about $90 \mathrm{wt} \%$ to about $15 \mathrm{wt} \%$. However, sodium emissions increased with the addition of calcium hydroxide. At $850^{\circ} \mathrm{C}$, sodium capture dropped from about $98 \%$ to $73 \%$ for pellets containing 10 wt\% calcium hydroxide. At $1100^{\circ} \mathrm{C}$, capture dropped from about $92 \mathrm{wt}^{\circ}$ to about $20 \mathrm{wt} \%$.

The Tennessee Valley Authority (TVA) is investigating acid hydrolysis of municipal waste to produce ethanol, and furfural as a means of producing useful products from municipal refuse. The cellulosic residue from the processing of newsprint is low in sulfur at 0.3 wt\% and low in ash at 0.7 wt\%. The TVA is interested in finding a use for this residue that would improve the economics of their process.

Test work indicated that the residue can function as an effective binder, but greater amounts of the material are required to produce equivalent compressive strengths than for a conventional binder such as corn starch and for the carbonate binding system investigated in this work. Also, some processing may be required to improve its binding properties, such as partial drying of the residue and some size reduction to allow it to be more uniformly mixed with the coal fines. It is not felt that either of these factors would be difficult to deal with on a scaled up basis.

The relative effectiveness of the residue as a binder would depend on its cost. If assigned a value of $\$ 25-30 /$ ton, the approximate cost of coal, the residue functions as effectively as corn starch as a binder. The lowsulfur residue has the added benefit of lowering the sulfur emissions of the pellets. 


\section{OBJECTIVES}

This research is a two-year effort with two goals which are complementary: work in goal one is directly applicable to goal two. The first goal was completed in year one. The second will be completed in year two.

1) Production of Compliance Stoker Fuel from Fine Illinois Coal - The first goal was to investigate factors relevant to producing a stoker fuel from Illinois coal fines with potential to burn at the year 2000 compliance sulfur dioxide emission limit of $1.2 / \mathrm{lbs} / \mathrm{MBtu}$. An Illinois coal with $1.6 \%$ sulfur was selected for this goal. Approximately $50 \%$ sulfur capture would be required to allow this coal to meet the compliance emission limit. Three tasks were performed for goal one.

Task 1 - Pellets were formed using a laboratory version of a commercially available pelletizer - a California Pellet Mill (CPM). Tests were conducted at CPM's Crawfordsville, Indiana, facility.

Task 2 - The Tennessee Valley Authority (TVA) is investigating acid hydrolysis as a method for producing ethanol and furfural from municipal waste. The residue from the processing of newsprint is low ash $(0.7 \%)$ and low sulfur $(0.3 \%)$ with an energy content of $9300 \mathrm{Btu} / 1 \mathrm{~b}$. Residue from this process was evaluated for its binding properties. Inclusion of this low sulfur residue in the pellets would increase the potential for achieving compliance sulfur emissions in a stoker boiler.

Task 3 - The effect of calcium hydroxide content on chlorine emissions was determined for this high chlorine coal. Pellets containing 0, 5, and $10 \mathrm{wt} \%$ calcium hydroxide were tested.

2) Determination of a General Approach to the Production of Carbonated Coal/Calcium Hydroxide Pellets - Previous results have indicated that effective binder levels and carbonation conditions vary as a function of particle size and moisture content. The equipment used for pelletization also may depend upon the particle size and moisture content of the coal fines due to materials handling considerations. Goal two is to determine a general approach for pelletizing and carbonating coal/calcium hydroxide pellets. Three tasks comprise this goal.

Task 4 - Tests will be conducted using IBC-106 ground to several particle sizes to determine the relationship among moisture and binder content and particle size on pellet quality. Several moisture contents and binder levels will be tested.

Task 5 - Extrusion will be evaluated as a method of pelletizing Inlinois coal fines using an extruder located at the Ceramic Engineering Building of the University of Illinois. An extruder may be an effective method of pelletization because it can be used to mix the coal fines and calcium hydroxide. 
Task 6 - To determine if combustion gas or gas from limestone calcination could be used as a source of carbon dioxide for carbonation, the effect of increased gas temperature on carbonation and pellet quality will be investigated. Carbon dioxide concentrations corresponding to that resulting from combustion or calcination will be utilized.

To potentially further reduce processing costs, an "encapsulation" approach to carbonation will be investigated. By encapsulation it is meant that just the outer portion of the pellet will be reacted to harden and weatherproof it.

\section{INTRODUCTION AND BACKGROUND}

This research represents a continuation of two projects (Rapp, et al., 1990 and 1991) co-funded by the Center for Research on Sulfur in Coal (CRSC), and the Army Engineering Research Lab (CERL). The CRCS's interest in funding the previous work has been to develop a method for utilizing Illinois coal fines that, in many cases, are currently being disposed of in tailing ponds. CERL's interest has been to develop a fuel for their stoker boilers that will burn at the year 2000 compliance sulfur dioxide emission level.

Results previously attained in this research indicate that when pellets are formed with sufficient calcium hydroxide $(5-10 \%$ for $90 \%-28$ mesh coal fines), carbonation produced significant improvements in compressive strength, impact and attrition resistance, and weatherability (Rapp, et al., 1991).

of significance is that carbonated pellets maintain their integrity while stored under water, while non-carbonated pellets or pellets formed with corn starch, a conventional binder, tend to disintegrate when immersed in water. The "weatherproofing" is likely due to the pellet being held together by the cementitious matrix of calcium carbonate which forms when a pellet is carbonated, and to the conversion of soluble calcium hydroxide to insoluble calcium carbonate.

Combustion testing conducted in a laboratory furnace at $850^{\circ} \mathrm{C}$ on pellets containing 2.6 wt\% sulfur Illinois No. 6 seam coal fines and 10 wt\% calcium hydroxide (a $2.3 / 1 \mathrm{Ca} / \mathrm{S}$ ratio) resulted in sulfur captures of greater than 70\% (Rapp, et al., 1991). A temperature of $850^{\circ} \mathrm{C}$ is in the range of operation of fluidized-bed combustors.

\section{The Carbonation Reaction}

For calcium hydroxide, the carbonation reaction is:

$$
\mathrm{Ca}(\mathrm{OH})_{2}+\mathrm{CO}_{2}+\mathrm{H}_{2} \mathrm{O} \rightarrow \mathrm{CaCO}_{3}+2 \mathrm{H}_{2} \mathrm{O}+19.6 \mathrm{kCal} \text {. }
$$

The reaction is an ionic reaction with water acting as a solvent for both the carbon dioxide and calcium hydroxide. The proposed mechanism involves 
the dissolution of the $\mathrm{Ca}(\mathrm{OH})_{2}$ to produce $\mathrm{Ca}++$ and $\mathrm{OH}$ - ions. The carbon dioxide dissolves to form $\mathrm{HCO}_{3}^{-}, \mathrm{CO}_{3}--$ and $\mathrm{H}+$ ions. The $\mathrm{Ca}++$ and $\mathrm{CO}_{3}--$ ions react to form insoluble calcium carbonate (Moorehead, et al., 1975). As shown, carbonation produces a net increase in water in the system.

Key factors influencing the rate of carbonation for pellets are the concentration of carbon dioxide content in the carbonating gas and the moisture content of the pellet. If too much moisture is present in a pellet, the pore spaces are filled and the carbon dioxide must diffuse through the water to reach the calcium hydroxide and react. This can severely slow the reaction. The ideal situation for the reaction to proceed is when there is enough moisture to coat the calcium hydroxide but leaving an open pore structure for the rapid ingress of carbon dioxide.

\section{EXPERIMENTAL PROCEDURES}

\section{Materials}

The fine coal sample used in this work was collected from a south-central Illinois preparation plant. The sample was mined from the Springfield (Illinois No. 5) seam and was obtained after dewatering by a screen bowl centrifuge. The sample is a composite concentrate from flotation circuitry and a collection of spiral concentrators.

Two samples were collected. Early in the project year, four five-gallon buckets were collected for laboratory work. Later in the year, two 55gallon drums of sample were collected for the CPM tests. Separate samples were collected because it was felt that riffling the larger sample (drum quantity) to provide samples for laboratory work would be difficult because of the moisture content of the coal fines. Also, we did not want to expose the larger sample to air for the length of time it would take to riffle because the sample would likely dry to some extent. This was not desirable because we wanted to pelletize the sample at the moisture content it was dewatered to using the centrifuge. To guard against the potential for moisture loss, both samples were stored in sealed containers after collection. The "as received" moisture content for both samples was approximately $20 \%$ by weight.

The sample (see chemical analysis in Table 1) is low in sulfur for an Illinois coal at 1.6 wt: and relatively high in chlorine content at 0.4 wt\%. Sodium and arsenic contents were $0.1 \mathrm{wt} \%$ and $19 \mathrm{ppm}$, respectively. The mean particle size of the bucket sample is 104 microns (150 mesh) and the $90 \%$ passing size is 241 microns (approximately 60 mesh). The mean particle size of the barrel sample was significantly larger at 227 microns with a $90 \%$ passing size of 590 microns.

The calcium hydroxide used was a commercial sample prepared from Burlington seam limestone. The corn starch tested was obtained from a commercial grain processing facility. 
The cellulosic material used in Task 2 was obtained from laboratory tests conducted by the TVA using acid hydrolysis processing of waste newspaper (see chemical analysis in Table 2) to produce ethanol and furfural. The cellulosic residue is a by-product of the process.

\section{Procedures}

Mixing - The coal/binder mixtures were prepared by adding the desired wt\% of binder to a 125 gram (dry basis) coal sample. For the laboratory tests in Task 1, the mixture was blended for five minutes by hand. For Task 2, the mixture was blended for two minutes using a variable speed hand-held mixer. Mixtures were prepared and pellets formed at the "as collected" sample moisture content.

Pellet Formation - Pellets were formed using $1 / 2$ and $1 / 4$ " (inside diameter) stainless steel cylindrical molds and pistons, and a Carver hydraulic press. Pellets were approximately equal in height and diameter. The sample was placed in the mold, compacted for 10 seconds with the desired pressure, then was removed from the mold. Because pellet height was a function of the amount of sample placed in the mold, which varied slightly with each pellet, there were slight differences in pellet height.

For each mixture, a sample was removed to obtain a moisture content before pellet formation. Moisture content was determined by drying on a hot plate until no further weight loss due to evaporation was observed. Moisture content after pellet formation was also determined by removing three pellets and drying them on the hot plate.

Pellet Carbonation - Pellets were carbonated in a desiccator reaction chamber connected to a carbon dioxide reservoir at atmospheric pressure. The carbon dioxide reservoir consisted of a weather balloon filled with commercial grade $100 \%$ carbon dioxide. The procedure followed was to fill the weather balloon with carbon dioxide, close the valve to the balloon, place the pellets in the desiccator, evacuate the desiccator using the vacuum line (pressure of $250 \mathrm{~mm} \mathrm{Hg}$ absolute), then open the valve to the weather balloon to introduce the carbon dioxide into the desiccator. Carbonation times were one hour using this procedure.

After pellet formation and carbonation (except for determination of green strength), the pellets were dried for one hour using a vacuum drier set at $70^{\circ} \mathrm{C}$ and with a vacuum of approximately $125 \mathrm{~mm} \mathrm{Hg}$ pressure absolute. As a result of this drying, all cured pellets could be tested and compared on a "moisture free" basis.

Strength Testing - Pellets in Task 1 were tested for radial strength because pellets prepared using a CPM do not have planer ends. Pellets in Task 2 were tested for strength along the vertical axis because these laboratory prepared pellets have planer ends.

The force to achieve failure in radial strength testing is significantly less than for testing along the vertical axis. Also, the radial strengths are reported in lbs and not in psi, because the CPM pellets are irregular 
in length, and length is a factor used when converting the radial load to psi. Results for both tests reported are an average of four results.

Radial Compressive Strength (Tensile) - An Instron strength testing machine was used for this measurement. A pellet was positioned on its side, then a force was applied at $0.1 \mathrm{~mm} /$ minute and compression to failure recorded.

Vertical Compressive Strength - A Tinius-01sen compressive strength testing machine was used for this measurement. Cylindrical pellets were placed between two parallel plates, a load was applied at $0.5 \mathrm{~cm} / \mathrm{minute}$ and compression to failure was recorded.

Attrition Resistance Testing - For attrition resistance tests, pellets were placed on a 20 mesh sieve and shaken for 20 minutes on a laboratory Ro-tap sieve shaker. The pellets remaining on the sieve were then weighed and the \% loss calculated. For the $1 / 2$ and $5 / 8$ " pellets, four pellets were used for each test. For the 1/4" pellets, approximately 15 grams of pellets were used for each test.

Combustion testing - The apparatus used for combustion testing is shown in Figure 1 and consisted of a high-temperature furnace capable of operating at temperatures up to $1350^{\circ} \mathrm{C}$, a mullite combustion tube, two gas wash bottles, a LFE computerized temperature controller, a Dycor quadropole gas analyzer (QGA), and a Compaq personal computer. A second oxidation zone (filled with CuO and held at $800^{\circ} \mathrm{C}$ ) was made in the mullite tube to assure that all the volatiles are oxidized during combustion to $\mathrm{CO}_{2}$ and $\mathrm{SO}_{2}$ prior to exiting to the tube. The combustion furnace temperature was controlled by a thermocouple located in the center of the furnace outside of the mullite tube. A second thermocouple was positioned inside the mullite tube adjacent to the pellet to obtain a more accurate temperature profile of the pellet as it burns. As the combustion gases exited the mullite tube, a continuous sample was taken through a capillary tube and monitored for $\mathrm{CO}_{2}$ and $\mathrm{SO}_{2}$ by the QGA. The QGA, the LFE temperature controller, and the inside thermocouple was connected to the Compaq $\mathrm{PC}$ which controlled the data acquisition for each combustion experiment.

Combustion tests were performed using air with a flow rate of $560 \mathrm{cc} / \mathrm{min}$. For each test, the furnace was brought to the desired combustion temperature and the pellet was placed in the furnace (the pellets used were $1 / 4^{\prime \prime}$ in diameter and approximately equivalent in length). Combustion and monitoring of combustion gases by the QGA commenced immediately. Each test was run until the QGA output indicated $\mathrm{CO}_{2}$ emissions had ceased. Neutron Activation for chlorine, sodium and arsenic content was performed on combustion residues. For determination of sulfur capture, the residue from each combustion test was then acid leached to determine residual sulfur. Comparison of this value to the sulfur in the feed pellet, determined by ASTM methods, was use to determine sulfur capture. 


\section{RESULTS AND DISCUSSION}

\section{Task 1. California Pellet Mill (CPM) Test}

Laboratory production of pellets using a hydraulic press certainly has its merits, most notably in cost and availability of equipment. This method has its limitations though in generating data that is directly applicable to a scaled-up process because there is no way of relating the data obtained to a commercially available pelletizer. When preparing pellets in this manner, a wide range of compaction pressures and formation times can be used.

If an exceedingly high compaction pressure and extended compaction time is used, a high quality pellet may be produced, possibly with little or no binder. However, if the method of formation used has no direct applicability to a commercially available pelletizer, the significance of the data is questionable. In this research, every effort has been made to ensure that the data generated and research approach followed has as much "real world" meaning as possible.

The objective of Task 1 was to pelletize coal fines collected from an operating preparation plant using a laboratory version of a commercially available pelletizer and following a process flowsheet that would be practical on a production scale. Data collected would be compared to laboratory data generated on pellets formed using a hydraulic press with the objective of determining correlations between the two methods of pellet formation.

The results of the task indicate that the CPM is a very effective method of pelletizing $28 \times 0$ Illinois coal fines. The pellets prepared using the CPM were uniformly better than the pellets formed in the laboratory using the hydraulic press. Results of the tests are shown in Tables 3-4.

To prepare the CPM pellets, a 55-gallon drum of $28 \times 0$ coal fines, collected from an Illinois preparation plant, was transported to CPM's Crawfordsville, Indiana, facility. The coal fines were at the moisture content (20 wt $\%)$ they had been dewatered to at the plant using a centrifuge. Pellets were formed using a Series $\mathrm{CL}$ laboratory pellet mill.

Both $1 / 2$ and $1 / 4^{\prime \prime}$ diameter pellets were produced. The $1 / 2^{\prime \prime}$ pellets were formed containing no binder and with 5 and 10 wt\% calcium hydroxide. The $1 / 4$ " pellets were formed with 10 wt\% calcium hydroxide, with 2.5 wt\% corn starch and with a mixture of 2.5 wt\% corn starch and 8.5 wt\% calcium carbonate. Pellets containing calcium hydroxide were carbonated at Crawfordsville using a portable carbonator. A carbonating gas of $100 \%$ commercial grade carbon dioxide was used.

For the 1/4" CPM pellets, the strongest cured pellets were the pellets formed with corn starch with a strength of 42 lbs attained for the pellets formed with $2.5 \mathrm{wt} \%$ corn starch and a strength of $47.5 \mathrm{lbs}$ for the pellets containing $2.5 \mathrm{wt} \%$ corn starch and $8.5 \mathrm{wt} \%$ calcium carbonate. The pellets 
formed without binder had a strength of only 2.5 lbs. The non-carbonated pellets containing calcium hydroxide had a compressive strength of 12.5 lbs with strength increasing with 30 minutes of carbonation to 22.5 lbs.

Although the starch bound pellets had a high cured strength, the green strength was quite low at less than 4 lbs for both sets of starch bound pellets. Drying increased the strength of the starch bound pellets more than ten-fold. This finding is in accord with previous results attained in this project (Rapp, et al., 1991). The carbonated pellets had green strengths more than triple that for the starch bound pellets. The noncarbonated pellets have a strength more than double that of the starch bound pellets at 8.5 lbs. The green strength is quite important because this gives an indication of a pellets ability to withstand handling after formation.

These results compare well with studies performed by Consolidated Coal Company using corn starch and calcium oxide as binders (Wasson, 1991). For this work on -28 mesh Pittsburgh seam coal fines, 1/4" pellets formed with 4 wt\% calcium oxide had a green and dried strength of 4.4 and 5.2 lbs, respectively, for a feed of $19.1 \mathrm{wt} \%$ moisture. The starch bound pellets, formed from a feed of 20.1 wt\% moisture, had green and set strengths of 2.0 and 10.1 lbs. When a lower moisture content feed of 15.5 wt\% moisture was used, the green and dried strengths rose to 7.6 and 28.7 lbs, respectively.

For the $1 / 2$ " pellets, pellets formed with no binder had a cured strength of 3 lbs. Addition of 5 wt\% calcium hydroxide increased the strength to 15.5 lbs with strength increasing to 18.0 lbs at 10 wt $\%$ calcium hydroxide. For these pellets, carbonation did not appreciably improve the strength of the pellets.

To determine if the pellets would carbonate, pellets returned in sealed containers were carbonated in the desiccator reaction chamber for one hour. The pellets increased in strength to 34 lbs. The reason for the lack of strength increase for the pellets carbonated at Crawfordsville, is believed to be attributable to the carbonator not sealing well and it is felt that a high concentration of carbon dioxide was not maintained in the reactor.

The results for the laboratory prepared pellets can be seen in Figures 23. As seen, for the $1 / 2^{\prime \prime}$ diameter pellets containing 10 wt: calcium hydroxide, there is a correlation between the carbonated pellets formed with 6000 psi to the CPM pellets that were carbonated at the ISGS. The non-carbonated pellets, however, were only about $50 \%$ as strong as the CPM prepared pellets.

For the 1/4" pellets, there was not a good correlation between the laboratory prepared pellets and the CPM prepared pellets. The CPM prepared pellets were of significantly better quality than the pellets prepared using the hydraulic press. Surprisingly, the laboratory formed pellets did not increase in strength as compaction pressure was increased, at least within the range of compaction pressures tested. The effect was 
verified when the results were repeated. Attrition resistance testing of selected batches of both green and dried 1/4" pellets was also conducted as part of this task. The test involved placing a weighed portion of pellets on a sieve shaker for 20 minutes and measuring the amount of -20 mesh material produced.

The results are listed in Table 8 and indicate that pellets formed without binders have a minimal resistance to attrition. For these pellets, less fines were produced for the green pellets than for the dried pellets with 31.5 and 86.0 wt\% fines generation, respectively. For the pellets formed with calcium hydroxide, resistance to attrition improved considerably with an approximate 6-7 wt\% attrition loss for the green and dried pellets. Carbonation improved the resistance to attrition for the dried carbonated pellets to an only $2.9 \mathrm{wt} \%$ loss. The $2.5 \mathrm{wt} \%$ starch bound pellets also had a very good resistance to attrition with 6.5 and 0.9 wt\% loss to fines for the green and dried pellets, respectively.

\section{Task 2. Incorporation of TVA Cellulosic Residue}

In many portions of the country, including Illinois, there is an increasing concern over the amount of municipal waste reporting to landfills and over the future availability of sufficient landfill capacity to dispose of this waste. Recycling can play a role in addressing this problem but it is no panacea. The TVA is investigating acid hydrolysis of municipal waste to produce ethanol and furfural as a means of producing useful products from municipal refuse. The cellulosic residue from the processing of newsprint is low in sulfur at 0.3 wt\% and low in ash at 0.7 wt\%. The TVA is interested in finding a use for this residue that would improve the economics of their process for achieving compliance sulfur emissions in a stoker boiler.

The residue could be a desirous addition to coal pellets for several reasons. Namely, the material could serve as a binder, and because of the low sulfur content, would lower the concentration of sulfur dioxide emissions from the pellets.

Test work indicated that the residue can function as an effective binder, but greater amounts of the material are required to produce equivalent compressive strengths than for a conventional binder, such as corn starch, and for the carbonate binding system investigated in this work. Also, some processing may be required to improve its binding properties, such as partial drying of the residue and some size reduction to allow it to be more uniformly mixed with the coal fines. It is not felt that either of these factors would be difficult to deal with on a scaled-up basis.

The sample of residue the ISGS received from the TVA was rather lumpy and was only 30 wt\% solids. As such, the sample was difficult to mix with the coal fines, and initial attempts at forming pellets resulted in pellets that had small horizontal cracks immediately visible upon removal from the pellet mold. A small food processor was used to reduce the sample to a size that could be more evenly distributed through the coal fines. 
The residue was tested for effectiveness at two moisture contents. One was at the "as received" moisture and the other was after the residue had been fully dried in a vacuum drier and sieved to remove all particles greater than 20 mesh. The two extremes in moisture were chosen to determine if additional processing (i.e. drying and sieving) would make the residue more competitive with a higher cost binder such as corn starch $(13.5 \$ / 1 b)$.

After size reduction in the food processor, the wet material was dried and a sieve analysis was performed which indicated the product at this stage was approximately 70 wt\% -20 mesh.

For the dried material, the screened out +20 mesh material was further ground in the food processor and re-sieved until nearly all the material was less than 20 mesh. A sieve analysis of this product indicated the particle size was approximately $80 \mathrm{wt} \%-\angle B$ mesh. In the tables and graphs associated with this task, the two materials are referred to as the wet and dry TVA material.

The results from the test program may be observed in Table 5. Graphical representation of selected results are shown in Figures 4 through 6 . Figure 4 gives a good indication of the relative effectiveness of the TVA residues compared to a commercially available binder, corn starch, and to the carbonate binding system.

The results show that wet TVA material has superior binding properties to the dry material, and that the dry TVA material and calcium hydroxide function with similar effectiveness as binders. The carbonated pellets containing 10 wt\% calcium hydroxide have similar binding properties to the pellets formed with about 17 wt\% wet TVA material and with the pellets formed with about 1.7 wt\% corn starch.

Although it appears that the TVA material is significantly less effective than corn starch, the actual relative effectiveness depends on the value assigned to the TVA material. If assigned the value of $\$ 27 /$ ton which is in the range of cost for Illinois coal, it would cost $1.35 \$$ /pound, or $1 / 10$ th the cost of the starch. As may be observed on the graph, the binding effectiveness to achieve $400 \mathrm{psi}$ strength is about $1 / 10$ th of that of corn starch. The TVA material has the added positive factor of reducing the sulfur emissions of the coal fines.

Tests were also conducted to gauge the effectiveness of the TVA material when used in concert with calcium hydroxide and the carbonate binding system. Typical result are plotted in Figures 5 and 6 . Figure 5 shows the effectiveness of inclusion of increasing amounts of both wet and dry TVA material into pellets formed with 10 wt $\%$ calcium hydroxide. For the mixture of binders, addition of the dry material resulted in pellets with the greatest amount of compressive strength. As the ariount of wet TVA material was added to the mixture, the strength increase of pellets due to carbonation became relatively less substantial. 
This low increase in strength due to carbonation is attributed to the fact that as the amount of wet TVA material is introduced into the mixture, the amount of moisture in the pellets increases accordingly. This moisture fills the pores of the pellet and siows the rate of the carbonation reaction. Moisture also takes up space in the pellet matrix and reduces the packing density which also reduces strength.

Another representation of the interaction of the two binding methods is shown in Figure 6 . In this figure, the amount of dry TVA material was held constant at 10 wt\% as the amount of calcium hydroxide was increased. As seen, the increase in strength due to addition of calcium hydroxide and due to carbonation roughly paralleled the initial increase in strength provided by the dry TVA material. Similar trends were apparent for addition of 5 and 20 wt\% dry TVA material although the magnitude of the differences were varied with the amount of dry TVA material added.

The results of this test program indicate that the TVA material serves as an effective binder; the actual effectiveness of which will depend on the value assigned to the binding residue. The wet material serves as a more effective binder than the dry material when used as the only binder. When used with calcium hydroxide and the carbonate binding system, the dry material serves as a more effective binder.

\section{Task 3. Chlorine Capture Study}

Combustion tests were conducted on pellets containing 0,5 , and 10 wt\% calcium hydroxide. Pellets were analyzed for the amount of chlorine, sulfur, sodium, and arsenic retained in the ash. Tests were conducted at $850^{\circ} \mathrm{C}$ and $1100^{\circ} \mathrm{C}$ except for sulfur which was tested for at $850^{\circ} \mathrm{C}$. It was intended to test for chlorine, sodium and arsenic at 1100 and $1350^{\circ} \mathrm{C}$, but the combustion residues fused and formed a glassy deposit that was impossible to remove from the combustion boat to obtain a sample for analysis. Carbonated pellets were tested for the pellets formed with calcium hydroxide; for the pellets formed without calcium hydroxide, corn starch was used as a binder. The results are shown in Table 7.

The results indicate that calcium hydroxide was effective at retaining portions of the coals chlorine, sulfur, and arsenic in the ash. Sodium content in the ash decreased with increasing calcium hydroxide content.

Specifically, chlorine capture for tests conducted at $850^{\circ} \mathrm{C}$ ranged from essentially nil at 0 wt\% calcium hydroxide to over 19 wt\% at 10 wt\% calcium hydroxide. Results for tests at $1100^{\circ} \mathrm{C}$ were nearly identical to those attained at $850^{\circ} \mathrm{C}$.

For sodium, in tests conducted at $850^{\circ} \mathrm{C}$, essentially all the sodium was retained in the ash of the pellet for the pellet formed with no calcium hydroxide. For the pellets formed with 5 and $10 \mathrm{wt} \%$ calcium hydroxide, only about $72 \mathrm{wt \%}$ sodium was retained in the ash. At $1100^{\circ} \mathrm{C}$, this effect was more pronounced, with $91.7 \mathrm{wt} \%$ sodium retained in the ash for the pellet formed without calcium hydroxide, while the pellet formed with 10 wt: calcium hydroxide retained only $20 \mathrm{wt} \%$ sodium in the ash. 
The decrease of sodium in the ash is probably due to calcium replacing sodium in silicate minerals and forming calcium silicate minerals, which are more stable at higher temperatures than the sodium minerals. $X$-ray diffraction of the ash material would help determine the actual mineralogy involved in such reactions.

Results for arsenic capture show that at $850^{\circ} \mathrm{C}$ approximately $63 \mathrm{wt} \%$ arsenic was retained in the ash for the 0 wt\% calcium hydroxide pellets. This amount increased to essentially 100 wt\% for pellets containing 5 and 10 wt\% calcium hydroxide. For tests conducted at $1100^{\circ} \mathrm{C}$, only $10 \%$ arsenic was retained in the ash for the pellets formed with 0 wt $\%$ calcium hydroxide but about 86 wt\% arsenic was retained in the ash for the pellets formed with 10 wt\%.- .1 cium hydroxide.

Sulfur capture for this relatively low sulfur coal ranged from nil at 0 wt\% calcium hydroxide to $36 \mathrm{wt} \%$ at $5 \mathrm{wt} \%$ calcium hydroxide to $70 \%$ at 10 wt\% calcium hydroxide. These values are low considering that 5 and 10 wt\% calcium hydroxide correspond to $1.8 / 1$ and $3.7 / 1 \mathrm{Ca} / \mathrm{S}$ ratios.

\section{Evaluation as a Stoker Fuel}

To evaluate the potential of economically producing a stoker fuel that would comply with the sulfur dioxide emissions standards imposed by the CAAA's, two questions need be addressed. 1) Can acceptable quality pellets be produced on a production scale at a reaconable cost, and 2) at what sulfur dioxide emission level are these pellets likely to burn?

Pellet production tests performed using a laboratory version of a CPM indicated that quality pellets can be produced and that carbonation can effectively increase the strength of these pellets. An engineer from CPM estimated the cost of pelletization using a CPM to be $\$ 6.50-8.00 /$ ton including the cost of depreciation, taxes, power, maintenance, die and roll, and labor. Binder cost is excluded from this estimate. The Principal Investigator has learned that there is a coal company currently pelleting 111 inois Basin Coal fines using a CPM. They are using a starch binder at $5 \mathrm{wt} \%$ that costs approximately $5 \$ / 1 \mathrm{~b}$.

Pellets have been received from this facility and tested in the lab. Pellets tested were $5 / 8^{\prime \prime}$ in diameter and had been air-dried at the plant. The pellets tested were of very high quality with a tested crushing force to failure (tensile strength) of 72 ibs. Fines generated in attrition resistance testing were only 0.1 wt\%. These results were better than for any of the pellets pripared using the laboratory CPM. For example, the $1 / 2^{\prime \prime}$ (closest in diameter to the commercially-prepared pellets) laboratory carbonated CPM prepared pellets had a dried tensile strength of $38.51 \mathrm{bs}$ and a 4.4 wt\% fines generation.

The Principal Investigator showed samples of both the aforementioned pellets to Donald Fortik, Power Plant Mechanical Engineer for the University of Illinois Abbott Power Plant, which has two stoker-fired boilers. He stated that both set of pellets appeared to have good mechanical strength, but that a major concern when evaluating a fuel for 
the $U$ of I stoker is fines generation and the pellets in question would have to be able to withstand handling without generating too many fines which could disrupt the operation of a stoker.

Coal/sorbent pellets have been fired in stoker boilers by Battelle Columbus. Battelle specified that dried briquettes measuring $0.9 \times 0.75$ $\times 0.2^{\prime \prime}$ had to have a cured compressive strength of 20 psi (Conkle, et al., 1983). For calculating the load on pellets in psi for a tensile strength measurement, the formula is as follows:

Tension $(p s i)=\frac{2(\text { load })}{(3.14)(\text { diameter })(\text { length })}$

Applying this formula to the $1 / 2^{\prime \prime}$ CPM pellets shows that even the noncarbonated dried $10 \mathrm{wt \%}$ calcium hydroxide pellets would have a greater strength than 20 psi. The non-carbonated pellets have an 18 lbs crushing force and are approximately 5/8" in length (the pellets are irregular in length but most were $1 / 2$ to $3 / 4^{\prime \prime}$ in length). By this formula, the pellets would have a 36.7 psi tensile strength.

To meet the emission standard of 1.2 lbs sulfur dioxide $/ 10^{6} \mathrm{Btu}$ may be more problematic than producing a suitable quality pellet. The coal fines used in this work are low in sulfur for an Illinois coal and would burn with emissions of 2.45 lbs sulfur dioxide $/ 10^{6} \mathrm{Btu}$. To achieve the year 2000 compliance emission standard of $1.2 \mathrm{lbs} / 10^{6} \mathrm{Btu}$, just over 50 sulfur capture would be required.

Plant-scale tests conducted using coal/sorbent pellets in stoker boilers have reported sulfur captures of 25-50\% (Conkle, et al., 1983; Douglas, et al., 1990). Higher sulfur captures have not been attained because stokers operate at a temperature (about $1350^{\circ} \mathrm{C}$ ) above the decomposition temperature of calcium sulfate, the mineral formed when calcium oxide reacts with sulfur.

However, laboratory combustion studies conducted at the ISGS using a tube furnace coupled with a quadropole gas analyzer, have indicated that at $1350^{\circ} \mathrm{C}$, initial sulfur captures are appreciable but continued exposure to high temperature results in calcium sulfate decomposition and release of captured sulfur (Rapp, et al., 1991). This may indicate that improved sulfur capture is possible in a stoker if the residence time in the high temperature zone is reduced or the combustion temperature could be lowered.

If the $50 \%$ sulfur capture ceiling is accepted, there are still approaches that could be tried to allow for compliance with the emission standard. One potentially attractive option would be to co-fire the pellets with municipal waste which is generally very low in sulfur.

Argonne National Lab conducted a series of tests where up to 50 wt\% Refuse Derived Fuel (RDF) was fired with coal (Ohlsson, et al., 1990). The refuse had been pelletized with 0,4 , and 8 wt\% calcium hydroxide. The results indicated that up to $30 \mathrm{wt} \%$ RDF could be fired with coal without 
upsetting combustion stability in the bed. Fuel handling, slagging and clinkering problems were no worse than for firing only coal. If the stoker facility were modified, up to 50 wt\% RDF could be fired. Cofiring with low sulfur refuse would lower the suifur capture required to levels previously achieved in plant-scale tests of coal/sorbent pellets.

Another option to improve the chances of achieving compliance sulfur emissions would be to lower the sulfur content of the coal fines. This could be accomplished by using only -100 mesh coal fines rather than $28 x$ 0 coal fines. The finer sized material would likely have a greater amount of liberated pyrite which could be liberated by advanced coal cleaning techniques such as column flotation.

At the plant where the coal fines used in this work were collected, column flotation tests have been conducted using a $3^{\prime}$ diameter production scale column, and sulfur contents as low as 1.2 were achieved at greater than 90\% Btu recovery (Ehrlinger, et al., 1992). At this sulfur content, only 35\% suifur capture would be required to achieve compliance sulfur dioxide emissions. (It should be noted that sulfur contents in a coal seam can vary and that the lower sulfur content of the column concentrate may in part be due to the fact that lower sulfur coal fines were mined that day. In general though, finer coal, if cleaned properly, can be expected to have a lower sulfur content.)

One potential problem presented by use of -100 mesh coal fines could be the selection of equipment for pellet formation. The finer coal does not dewater to as low of moisture content as $28 \times 0$ fines and may be difficult to feed to a CPM.

\section{CONCLUSIONS AND RECOMMENDATIONS}

Tasks 1-3 have been completed as scheduled. Results indicate that a California Pellet Mill is an effective method of pelletizing $28 \times 0$ coal fines at the moisture content that is achievable using conventional dewatering techniques (i.e., a screen bowl centrifuge). This result is from tests performed using a laboratory version of a CPM. Also important to note is that pellets from $28 \times 0$ Illinois Basin coal fines are currently successfully produced on a production scale (20 tons/hr) using a CPM. Corn starch is being used as a binder at about 5 wt\% but as much as 7-8 wtr has been used.

In addition to completing Tasks 1-3, work on Task 4 for this project was commenced with the investigation of mixing techniques. This work, investigating the effect of particle size and moisture content on pellet quality, will continue next year. Also extrusion will be investigated as a method of pelletizing coal fines. The effect of temperature of the carbonating gas on the carbonation reaction will be investigated.

The Principal Investigator believes that particle size and moisture content interacting with production factors such as the equipment used for pellet formation will be key factors in developing a successful method of 
pelletizing coal fines. Successful scale-up of the work reported here and for any attempt at pelletizing coal fines will depend upon acknowledging and accounting for the fact that each variable and unit operation are interdependent.

\section{ACKNOWLEDGEMENTS}

The investigators would like to thank the CRSC and CERL for their support of this research. We also thank secretaries Carol Cobble and Cali Hobgood-Lemme for their assistance throughout the year.

\section{REFERENCES}

Conkle, H. N., W. J. Dawson, and B. W. Rising. 1983. Reconstitution of Coal and Limestone for Use in Industrial Stoker Boilers, From "Proceedings of the 18th Biannual Conference," International Briquetting Association, pp. 33-45.

Douglas, R. E., G. E. Wasson, and W. C. Cones. 1990. Stoker Boiler Operations with Briquetted Coal Fines, presented at the Counsel of Industrial Boiler Operations (CIPO), May 5.

Ehrlinger, H. P., J. M. Lytle, R. M. Sterner, D. M. Norris, J. W. Amos, and J. A. Christopherson. 1992. Fine Coal Flotation of Plant Waste: An In-Plant Comparison - Column vs Sub-A Cells, Final Report to the Center for Research on Sulfur in Coal.

Moorehead, D. R., and P. J. Morand. 1975. Some Observations of the Carbonation of Portlandite $\left(\mathrm{Ca}(\mathrm{OH})_{2}\right.$ and Its Relationship to the Carbonation Hardening of Lime Products, 3rd Symposium on Science and Research in Silicate Chemistry, Bras, Czechoslovakia.

Ohlsson, 0. 0., and K. E. Daugherty. 1990. Results of Emissions and Ash Testing in Full-scale Co-Combustion Tests of Binder-Enhanced ROF Pellets and High-Sulfur Coals, presented at the Air and Waste Management Association Forum 90, June 24-29.

Rapp, D. M., J. M. Lytle, K. C. Hackley, L. B.Kohlenberger, D. L. Moran, R. L. Berger, and K. Griggs. 1990. A Method for Improving Sulfur Capture Using Coal/Sorbent Pellets, Final Report to the Center for Research on Sulfur in Coal.

Rapp, D. M., J. M. Lytle, K. C. Hackley, D. L. Moran, R. L. Berger, and K. Griggs. 1992. Process Development for the Production of Coal/Sorbent Agglomerates, Final Report to the Center for Research on Sulfur in Coal.

Wasson, G. E. 1991. Extrusion Agglomeration of Fine Coal, presented at the 1991 Annual Meeting of the AIME/SME. 


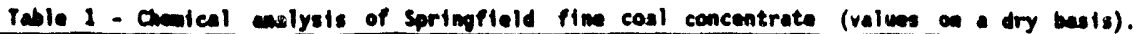

\begin{tabular}{|l|c|c|}
\hline & Bucket Sample & Sarrel Saaple \\
\hline \hline Ash & 9.7 & 9.2 \\
\hline Total Sulfur & 1.6 & 1.6 \\
\hline Pyritic Sulfur & 0.75 & 0.76 \\
\hline Organic Sulfur & 0.74 & 0.79 \\
\hline Sulfatic Sulfur & 0.11 & 0.05 \\
\hline Total chlorine & 0.4 & \\
\hline Hydrogen & 4.7 & \\
\hline Carbon & 14.9 & \\
\hline Nitrogen & 1.5 & \\
\hline Oxygen & 7.2 & \\
\hline Otulib & 13141 & 13253 \\
\hline
\end{tabular}

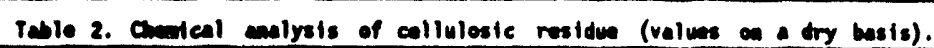

\begin{tabular}{||l|l|}
\hline Ash & 0.3 \\
\hline Total Sulfur & $n i l$ \\
\hline Hydrogen & 6.2 \\
\hline Carbon & 53.5 \\
\hline Nitrogen & 0.2 \\
\hline Oxygen & 39.8 \\
\hline Btu/10 & 9436 \\
\hline
\end{tabular}

Pable 3 - Acliel coproselve strangth in ibe crushim foree to fotlure

\begin{tabular}{|c|c|c|}
\hline Binder & Green Strength (16s) & Cured strength (16s) \\
\hline No Binder & 3.3 & 2.5 \\
\hline 10 wt $C_{a}(O H) 2$ & 8.5 & 12.5 \\
\hline 10 wt+ $\mathrm{Ca}_{1}(\mathrm{OH})_{2} \mathrm{CO}_{2} 5$ ain & 1.2 & 19:5 \\
\hline 10 wet $\mathrm{Ca}_{2}(\mathrm{OH})_{1}$. $\mathrm{CO}_{1}, 15 \mathrm{~min}$ & 11.5 & 14.9 \\
\hline 10 wtt $\mathrm{Ca}_{2}(\mathrm{OH})_{2}, \mathrm{CO}_{2} 30$ win & 11.5 & 22.5 \\
\hline 2.5 wtt cs & 2.5 & 12.0 \\
\hline 2.5 wtt CS, \& wtt Caco, & 3.6 & 47.5 \\
\hline
\end{tabular}

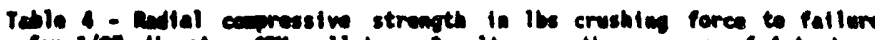

\begin{tabular}{|c|c|c|}
\hline Binder & Green strength (10s) & Cured Strength (10s) \\
\hline No Binder & 4.5 & 3.0 \\
\hline 5 wtt $\mathrm{Ca}_{2}(\mathrm{OH})_{2}$ & 7.5 & 15.5 \\
\hline $5 \mathrm{wt}+\mathrm{Ca}_{\mathrm{A}}(\mathrm{OH})_{2 .} \mathrm{CO}_{3} \cdot 15 \mathrm{~min}$ & 11.0 & 17.5 \\
\hline 10 wet $\mathrm{Ca}(\mathrm{OH})_{2}$ & 12.0 & 18.0 \\
\hline 10 wtt $\mathrm{Ca}_{2}(\mathrm{OH})_{2}, \mathrm{CO}_{2} 15=\mathrm{in}$ & 14.5 & 18.5 \\
\hline $10 \mathrm{wt}+\mathrm{Ca}_{\mathrm{a}}(\mathrm{OH})_{2} \mathrm{CO}_{4}$ des." & & 34.0 \\
\hline
\end{tabular}

- $\mathrm{CO}_{2}$ incrcates carbonated pellets 
Table 5 - Results fro TVA Test Matrix. Copressive strength wesured along the vertical axis and is in pst to fatlure. Results are the average of 4 tests.

\begin{tabular}{|c|c|c|c|}
\hline $\begin{array}{l}\text { WTH TVA } \\
\text { Residue* }\end{array}$ & Wtt $\mathrm{Ca}(\mathrm{OH})_{2}$ & Carbonated"* & $\begin{array}{c}\text { Conpressive Strength } \\
\text { (psi) }\end{array}$ \\
\hline 0 & 0 & $x$ & 5 \\
\hline 0 & 5 & $n$ & 85 \\
\hline 0 & 5 & $y$ & 180 \\
\hline 0 & 10 & $n$ & 110 \\
\hline 0 & 10 & $y$ & 390 \\
\hline $5 w$ & 0 & $x$ & 165 \\
\hline $5 d$ & 0 & $x$ & 80 \\
\hline $5 v$ & 5 & $n$ & 205 \\
\hline $25 x$ & 5 & $y$ & 240 \\
\hline Sd & 5 & $n$ & 91 \\
\hline $5 d$ & 5 & $y$ & 186 \\
\hline 5u & 10 & $n$ & 175 \\
\hline $5 n$ & 10 & $y$ & 355 \\
\hline $5 d$ & 10 & $n$ & 180 \\
\hline $5 d$ & 10 & $y$ & 480 \\
\hline $10 x$ & 0 & $x$ & 230 \\
\hline $10 d$ & 0 & $x$ & 105 \\
\hline $10 x$ & 5 & $n$ & 270 \\
\hline 100 & 5 & $y$ & 255 \\
\hline $10 d$ & 5 & $n$ & 187 \\
\hline $10 \mathrm{~d}$ & 5 & $y$ & 300 \\
\hline $10 y$ & 10 & $n$ & 270 \\
\hline $10 \mathrm{x}$ & 10 & $y$ & 355 \\
\hline $10 d$ & 10 & $n$ & 240 \\
\hline $10 d$ & 10 & $y$ & 540 \\
\hline $20 y$ & 0 & $x$ & 480 \\
\hline $20 d$ & 0 & $x$ & 210 \\
\hline $20 v$ & 5 & $n$ & 450 \\
\hline 20 & 5 & $y$ & 460 \\
\hline $20 \mathrm{~d}$ & 5 & $n$ & 245 \\
\hline $20 \mathrm{~d}$ & 5 & $y$ & 490 \\
\hline $20 \times$ & 10 & $n$ & 495 \\
\hline $20 w$ & 10 & $y$ & 545 \\
\hline $20 d$ & 10 & $n$ & 370 \\
\hline $20 d$ & 10 & $y$ & 675 \\
\hline
\end{tabular}


Table 6. Results of compressive strength testing performed along the vertical axis on pellets formed with corn starch as a binder. Results reported are in psi crushing force to failure and are the average of 4 iests.

\begin{tabular}{|c|c|}
\hline WTr Corn Starch & Compressive Strength (psi) \\
\hline 0.5 & 180 \\
\hline 1.0 & 365 \\
\hline 2.0 & 560 \\
\hline
\end{tabular}

Table 7. Results from combustion testing conducted in a laboratory tube furnace.

\begin{tabular}{|c|c|c|c|c|c||}
\hline $\begin{array}{c}\text { Wt\% } \\
\mathrm{Ca}(\mathrm{OH})_{2}\end{array}$ & $\begin{array}{c}\text { Combustion } \\
\text { Temp. }{ }^{\mathrm{C}}\end{array}$ & $\begin{array}{c}\text { \% Chlorine } \\
\text { Capture }\end{array}$ & $\begin{array}{c}\text { * Sodium } \\
\text { Capture }\end{array}$ & $\begin{array}{c}\text { * Arsenic } \\
\text { Capture }\end{array}$ & $\begin{array}{c}\text { \% Sulfur } \\
\text { Capture }\end{array}$ \\
\hline 0 & 850 & nil & 97.9 & 62.7 & nil \\
\hline 5 & 850 & 5.5 & 72.6 & 99.4 & 36 \\
\hline 10 & 850 & 19.3 & 72.2 & 100.0 & 70 \\
\hline 0 & 1100 & $n i 1$ & 91.7 & 10.3 & \\
\hline 10 & 1100 & 22.9 & 20.5 & 86.2 & \\
\hline
\end{tabular}

Table 8. Results from attrition resistance testing of $1 / 4^{*}$ diameter CPM pellets. Value listed is the wt: of pellets remaining on a 20 mesh sieve after shaking on a Ro-Tap sieve shaker for 20 minutes. $\mathrm{CO}_{2}$ indicates a carbonated pellet.

\begin{tabular}{|l|c|c|}
\hline \multicolumn{1}{|c|}{ Binder } & $\begin{array}{c}\text { Wtr Loss } \\
\text { (green pellets) }\end{array}$ & $\begin{array}{c}\text { Wt? loss } \\
\text { (dried pellets) }\end{array}$ \\
\hline No Binder & 31.5 & 86.0 \\
\hline 10 wt* $\mathrm{Ca}(\mathrm{OH})_{2}$, & 6.4 & 7.2 \\
\hline 10 wt\& $\mathrm{Ca}(\mathrm{OH})_{2}, \mathrm{CO}_{2} 5$ min & 14.2 & 2.9 \\
\hline 2.5 wtz $\mathrm{CS}$ & 6.5 & 0.9 \\
\hline
\end{tabular}




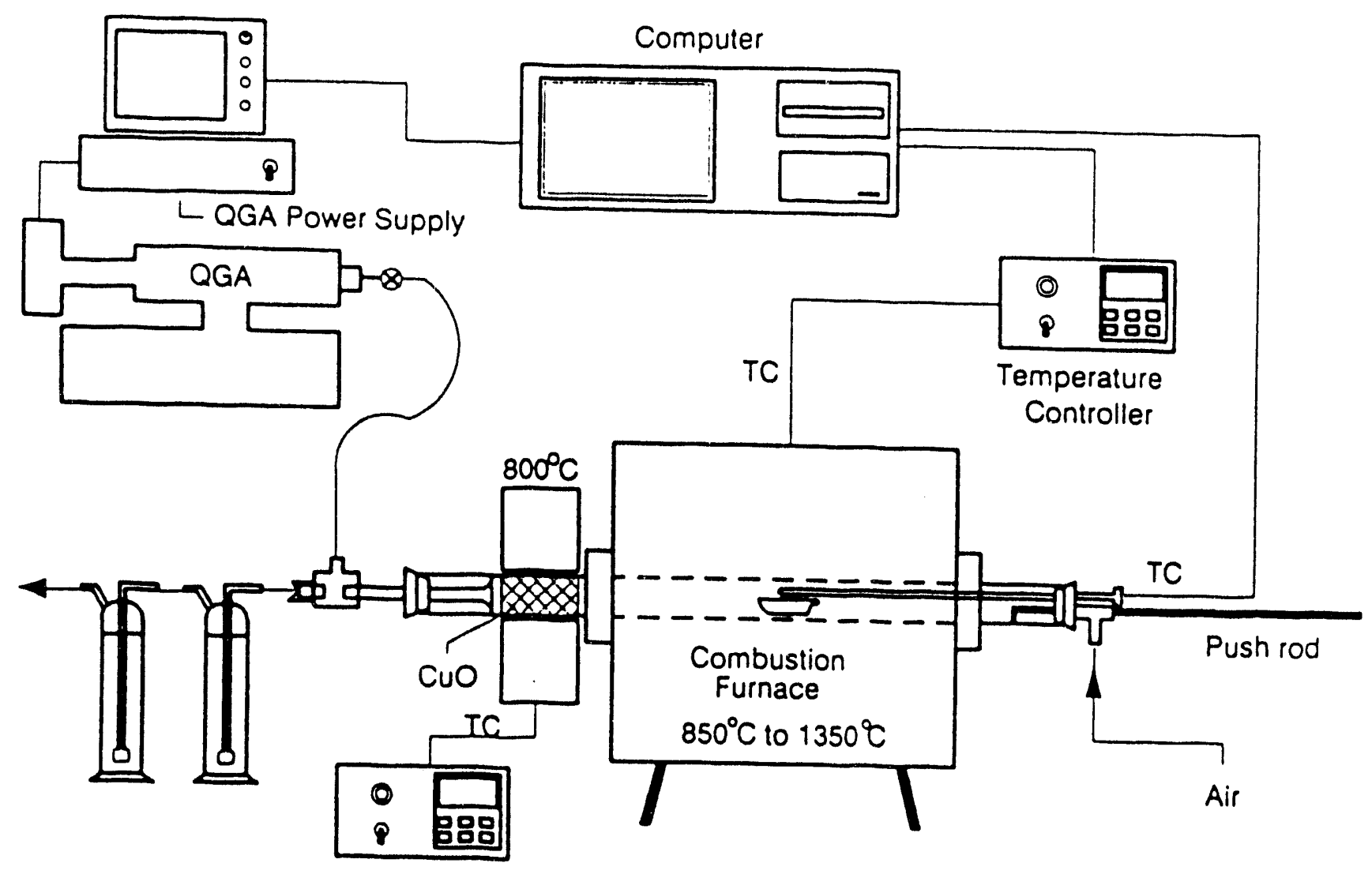

Figure 1.- Schematic of combustion testing equipment 


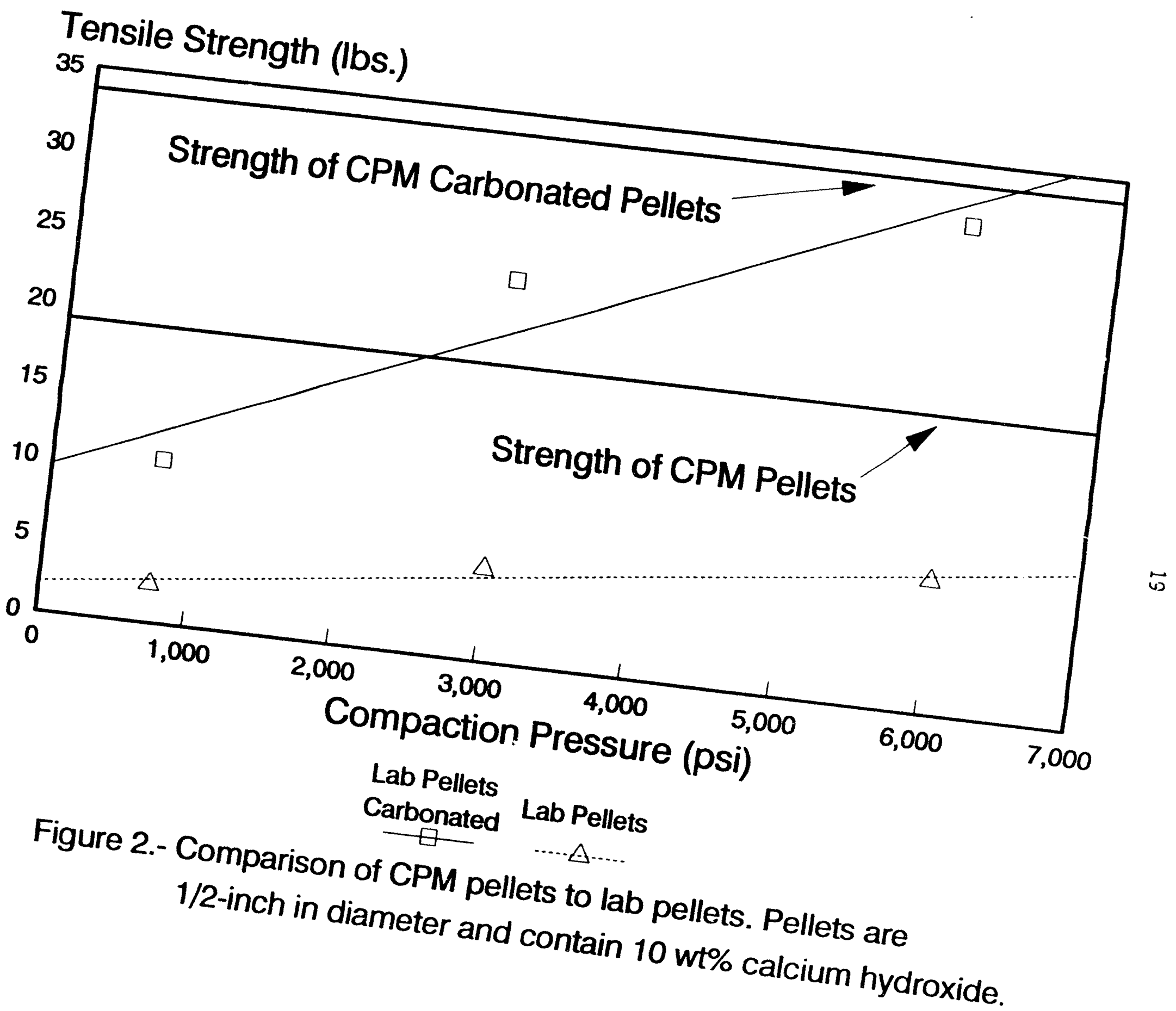




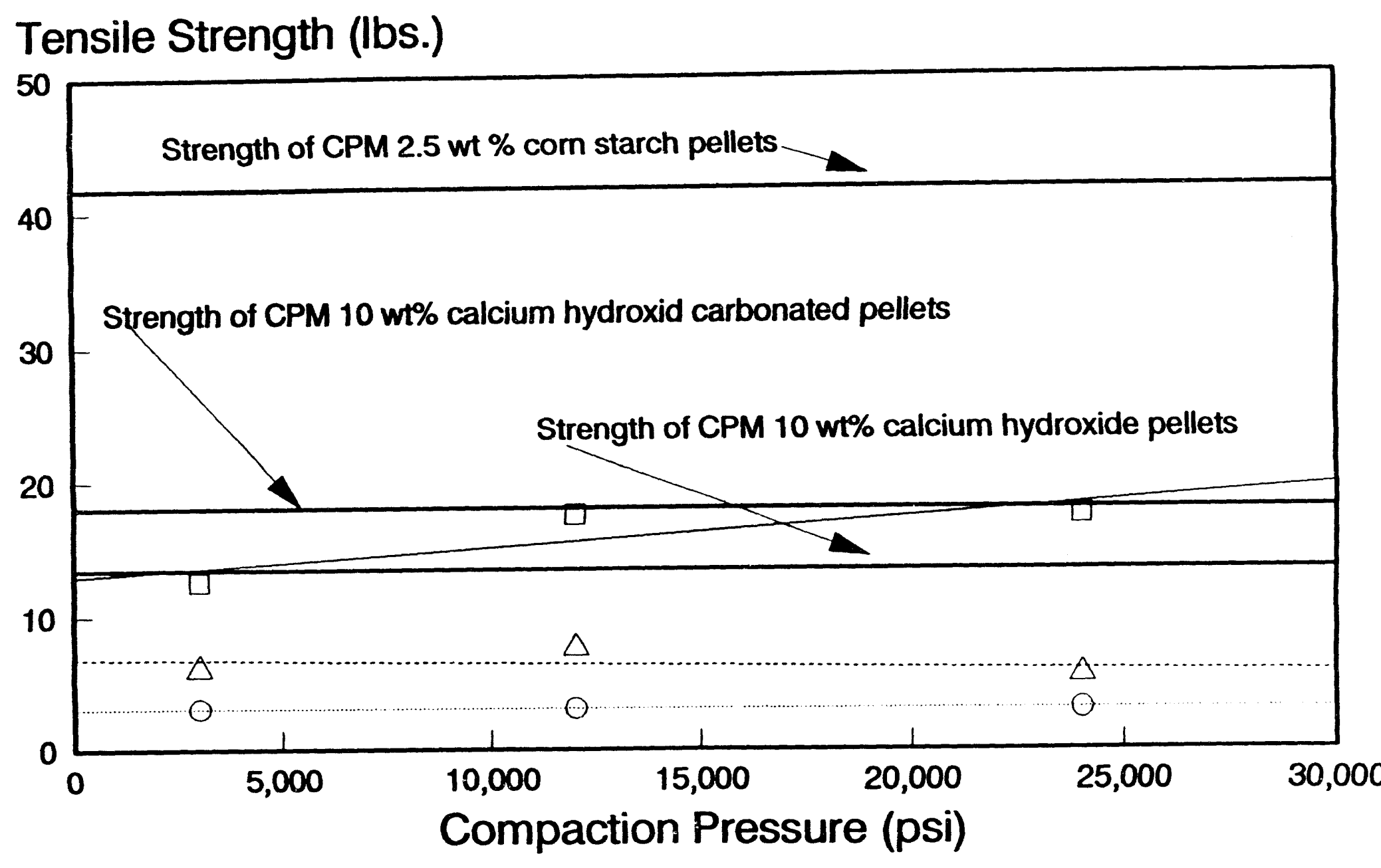

2.5 wt\% corn starch 10 wt\% $\mathrm{Ca}(\mathrm{OH}) 2$

$\begin{array}{lcc}\text { pellets } & \text { Carbonated } & 10 w t \% \mathrm{Ca}(\mathrm{OH}) 2 \\ \square & \cdots & \bigcirc\end{array}$

Figure 3.- Comparison of CPM pellets to lab pellets. Pellets are $1 / 4$-inch in diameter. 

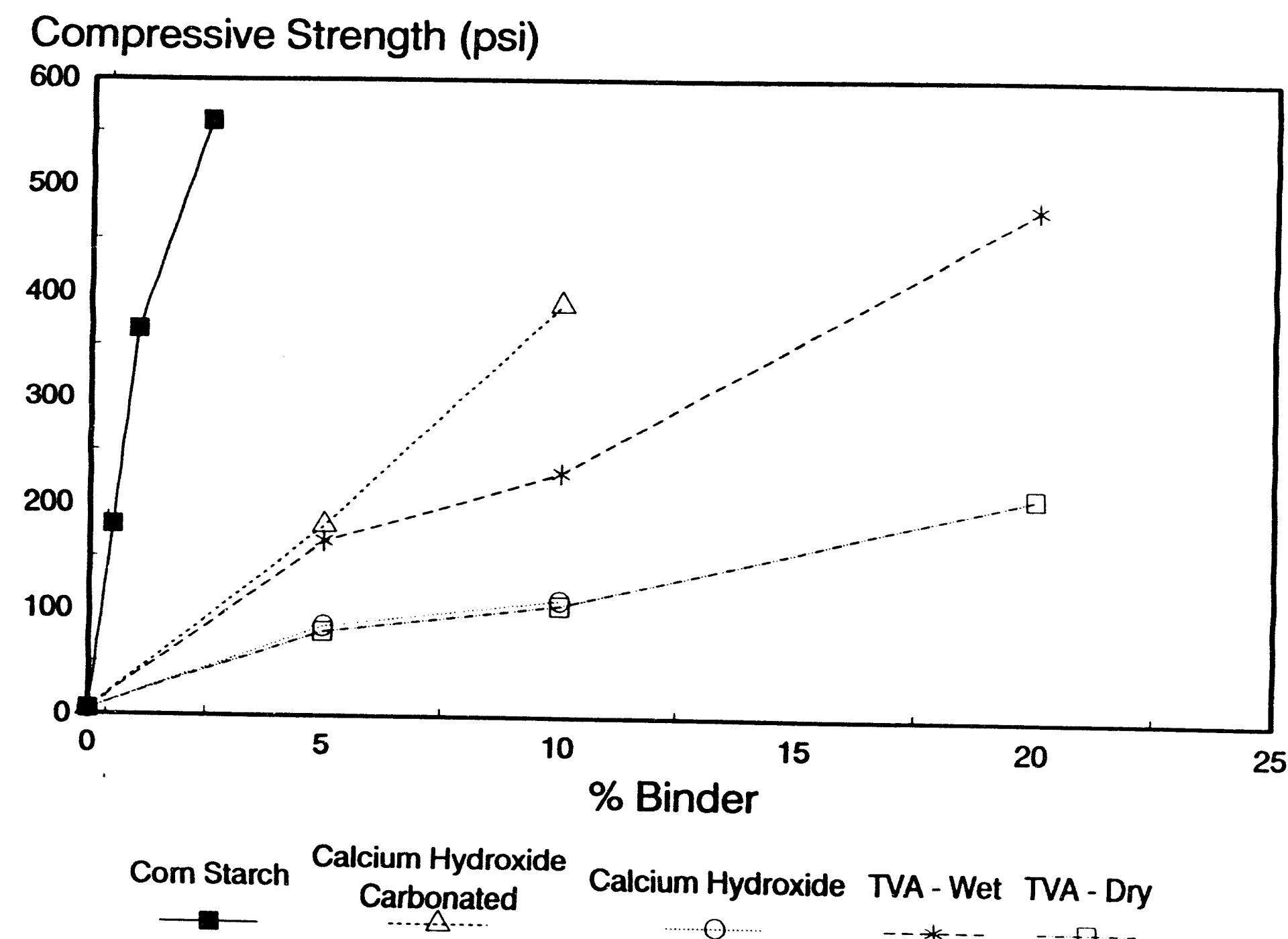

Figure 4.- Compressive strength as a function of binder content. 


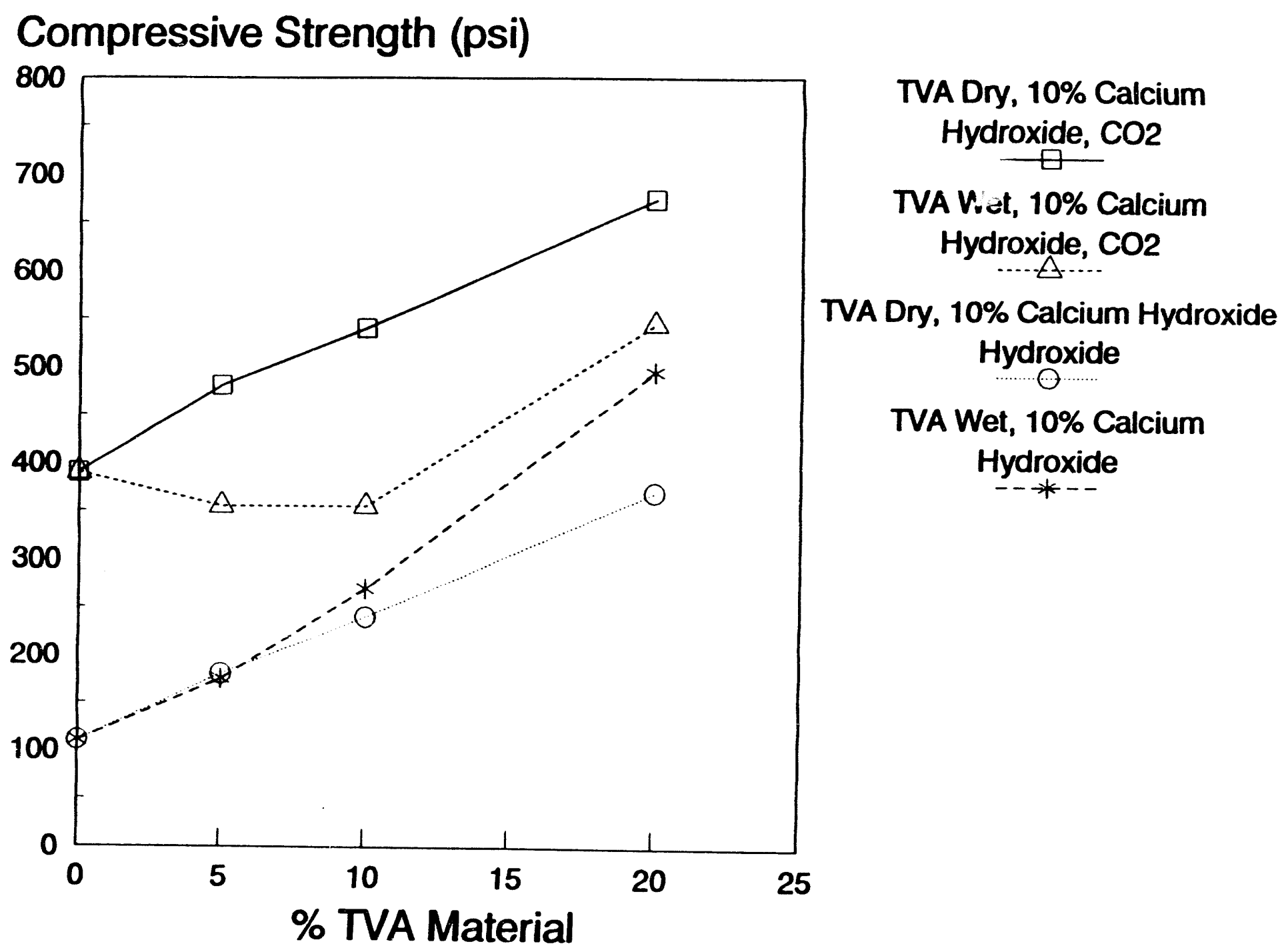

Figure 5.- Effect of increasing TVA residue content on strength development due to carbonation. 


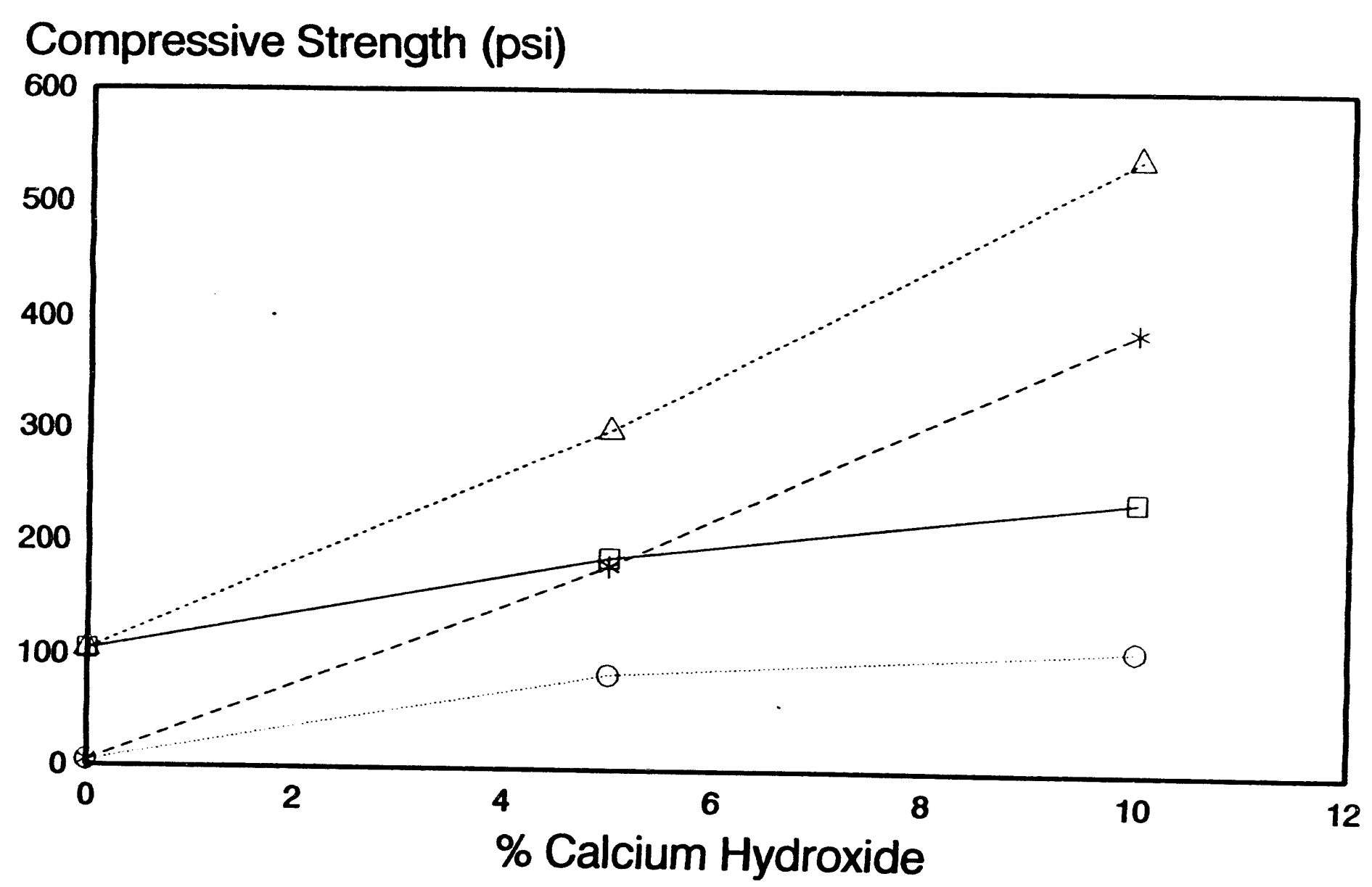

Calcium Hydroxide Calcium Hydroxide 10\% Dry TVA 10\% Dry TVA, CO2

Calcium Hydroxide

○

Calcium Hydroxide

Carbonated

Figure 6.- Effect of increasing calcium hydroxide content on strength development for pellets containing 10 wt\% dry TVA residue. 
PROJECT MANAGEMENT REPORT

September 1, 1991 through August 31, 1992

Project Title: CARBOMATION AS A BIMDING MECHANISM FOR COAL/CALCIUM
HYDROXIDE PELLETS

Priricipal Investigator:

David M. Rapp. Illinois State Geological Survey (ISGS)

615 E. Peabody Orive

Champaign. IL 61820

(217) 244-4991

Co-Investigators:

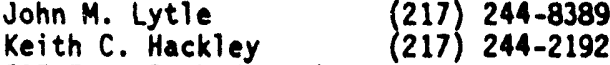

615 East Peabody Drive

Champaign. IL 61820

Richard Strickland

Tennessee Valley Authority

Muscle Shoals. AL 35660

(205) $386-2542$

Project Monitor: Dr. Dan Banerjee

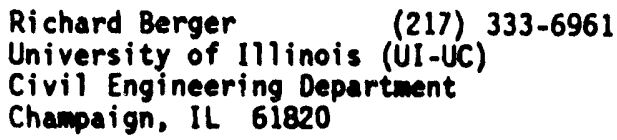

(217) 398-5505

Construction Engineering Research Lab Champaign, IL 61820

\section{COMNENTS}

A budget change per the July 28, 1992 letter to the CRSC is reflected in Exhibit B.

This project is funded by the U. S. Department of Energy (PETC) and by the Illinois Department of Energy and Natural Resources as part of their costshared programs. 


\section{EXPENDITURES - EXHIBIT B}

Projected and Estimated Actual Expenditures by Quarter

\begin{tabular}{|c|c|c|c|c|c|c|c|c|}
\hline $\begin{array}{c}\text { Quarter } \\
\text { (cumulative } \\
\text { by quarter) }\end{array}$ & $\begin{array}{l}\text { Types of } \\
\text { Cost }\end{array}$ & $\begin{array}{l}\text { Direct } \\
\text { Labor }\end{array}$ & $\begin{array}{c}\text { Materials } \\
\text { and } \\
\text { Supplies }\end{array}$ & Travel & $\begin{array}{c}\text { Major } \\
\text { Equipment }\end{array}$ & $\begin{array}{l}\text { Other } \\
\text { Direct } \\
\text { Costs } \\
\end{array}$ & $\begin{array}{l}\text { Indirect } \\
\text { Costs }\end{array}$ & Total \\
\hline \multirow{2}{*}{$\begin{array}{l}\text { Sept. } 1, \text { to } \\
\text { Nov. } 30,1991\end{array}$} & Projected & 12,529 & 268 & 0 & 0 & 4,846 & 1,764 & 19,407 \\
\hline & Est. Actual & 12,529 & 65 & 0 & 0 & 1,893 & 1,163 & 15,650 \\
\hline \multirow{2}{*}{$\begin{array}{c}\text { Sept. } 1,1991 \\
\text { to } \\
\text { Feb. } 28,1992 \\
\end{array}$} & Projected & 25,058 & 536 & 0 & 0 & 9,693 & 3,529 & 38,816 \\
\hline & Est. Actual & 25,058 & 90 & 0 & 0 & 4,220 & 1,193 & 30,561 \\
\hline \multirow{2}{*}{$\begin{array}{c}\text { Sept. } 1,1991 \\
\text { to } \\
\text { May } 31,1992 \\
\end{array}$} & Projected & 37,587 & 804 & 1,200 & 0 & 14,540 & 5,413 & 59,544 \\
\hline & Est. Actual & 37,587 & 399 & 0 & 0 & 6,733 & 2,290 & 47,009 \\
\hline \multirow{2}{*}{$\begin{array}{c}\text { Sept. } 1,1991 \\
\text { to } \\
\text { Aug. } 31,1992\end{array}$} & Projected & 50,117 & 1,072 & 650 & 47,000 & 15,287 & 7,183 & 79,009 \\
\hline & Est. Actual & 50,953 & 1,178 & 715 & 47,000 & 14,280 & 7,183 & 79,009 \\
\hline
\end{tabular}


REVISED COST BY QUARTER - EXHIBIT C

CARBONATION AS A BINDING MECHANISM FOR COAL/CALCIUM HYDROXIDE PELLETS

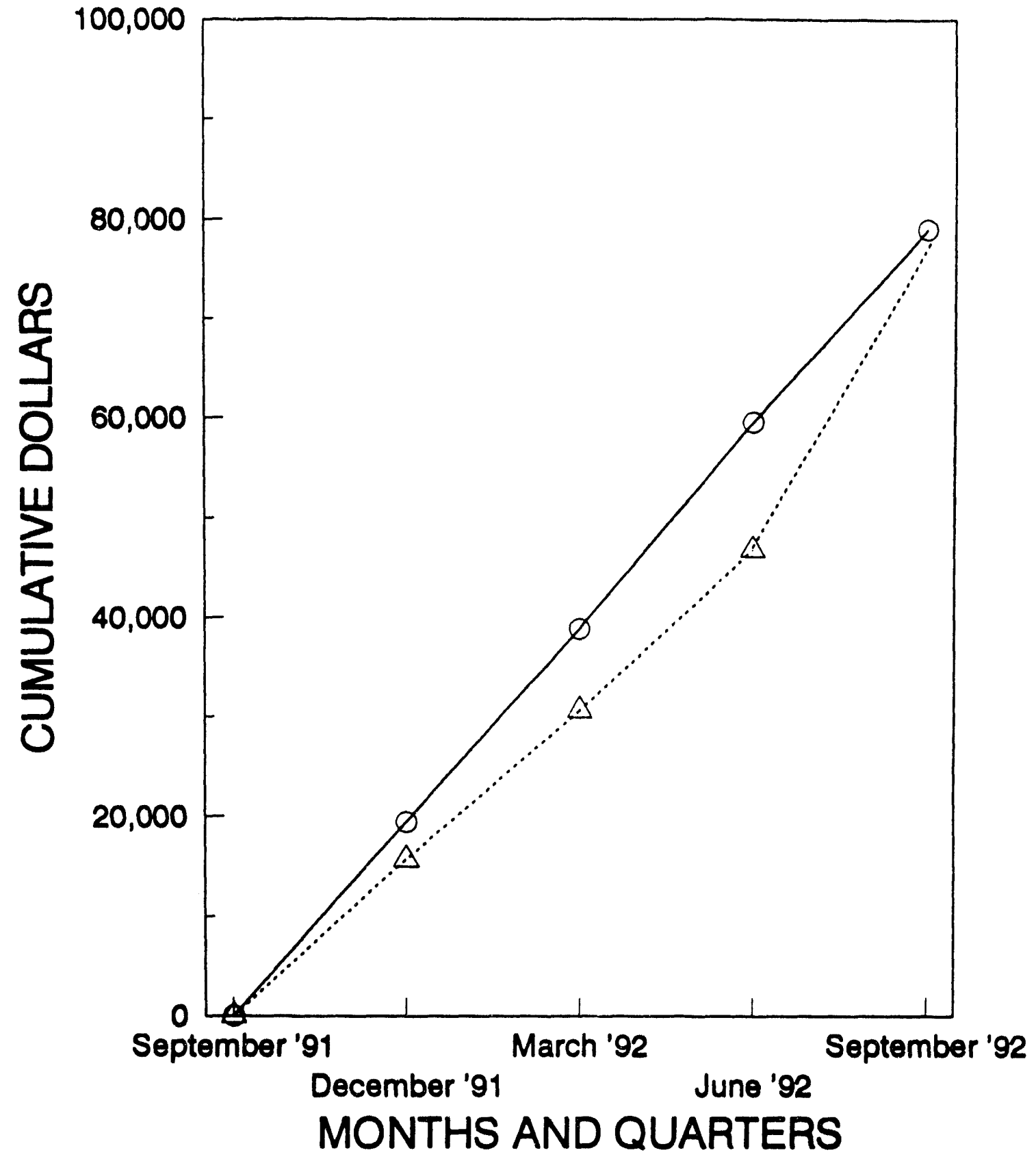

- Projected Expenditures $\$ 79,009$

$\ldots \leftrightarrow$ Actual Expenditures $\$ 79,009$

TOTAL CRSC AWARD $\$ 79,009$ 
SCHEDULE OF PROJECT MILESTONES

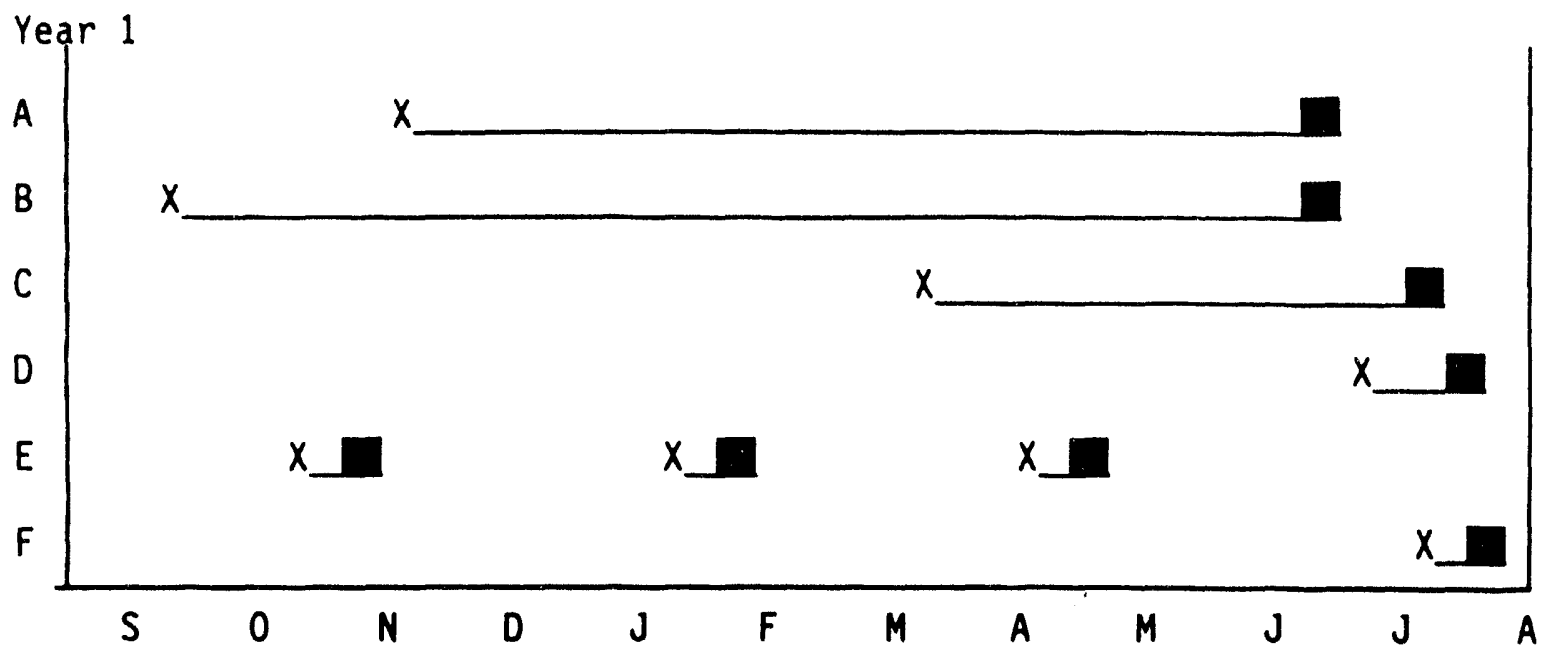

Milestones:

A. California Pellet Mill Test

B. Incorporation of TVA Cellulosic Residue

C. Chlorine Capture Study

D. Particle Size, Moisture, Binder Level Study

E. Quarterly Reports

F. Final Report 

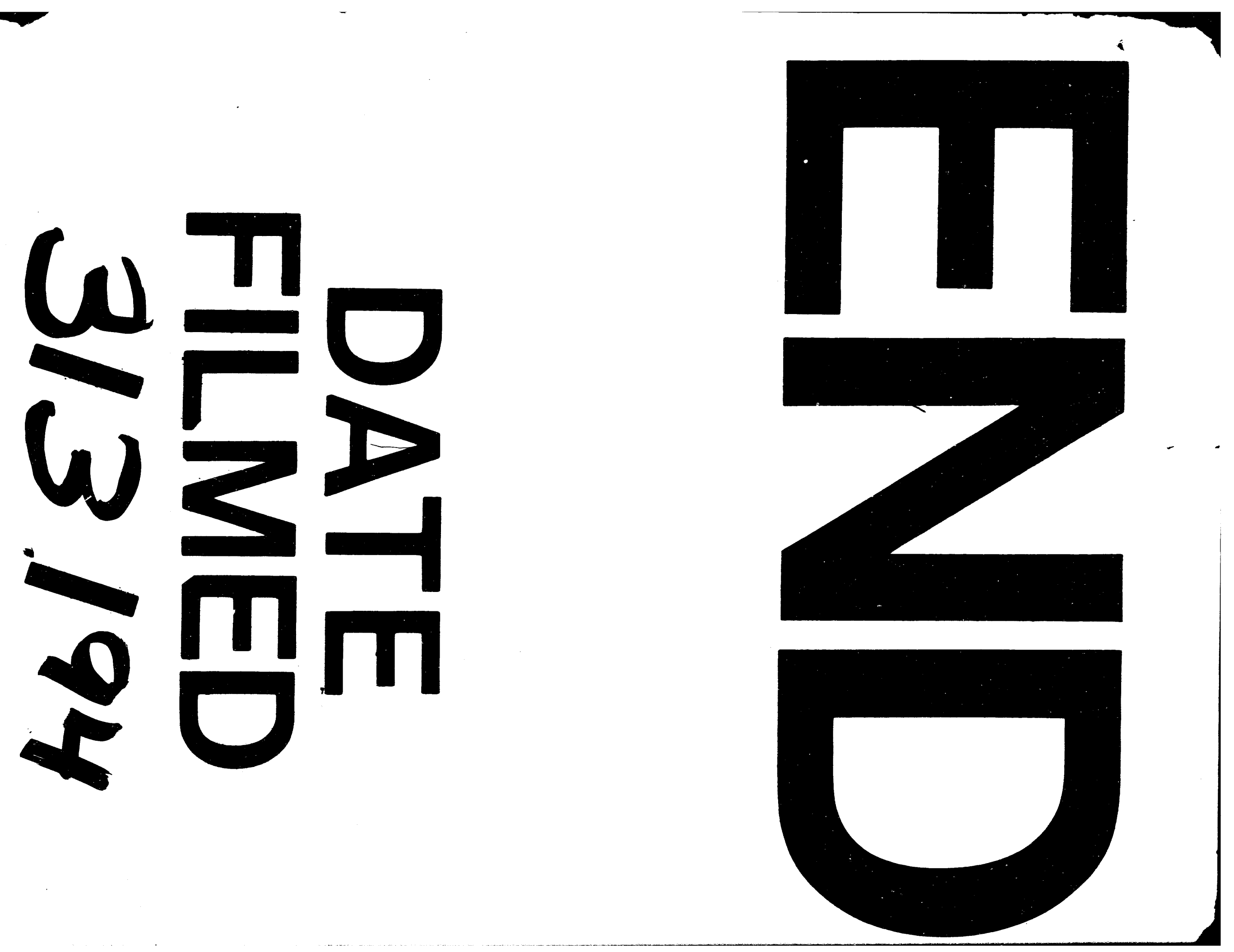
. 